\title{
Foraging strategy of a top predator in tropical waters: great frigatebirds in the Mozambique Channel
}

\author{
Henri Weimerskirch ${ }^{1,3, *}$, Matthieu Le Corre ${ }^{2}$, Sébastien Jaquemet ${ }^{2}$, Michel Potier ${ }^{1}$, \\ Francis Marsac ${ }^{1}$
}

\author{
${ }^{1}$ Institut de Recherche pour le Développement, Centre de la Réunion, UR 109 Thetis, BP 172, 97492 Sainte Clotilde, \\ Ile de la Réunion, France \\ ${ }^{2}$ Laboratoire d'Ecologie Marine, Université de la Réunion, 15 avenue René Cassin, BP 7151, 97715 Saint Denis,
} Ile de la Réunion, France

${ }^{3}$ Present address: Centre d'Etudes Biologiques de Chizé, Centre national de la Recherche Scientifique, 79360 Villiers en Bois, France

\begin{abstract}
Although oceanic tropical waters occupy almost $50 \%$ of the total area of pelagic oceans, knowledge of the foraging ecology of top predators in these low productivity waters is limitied. This is particularly the case for tropical seabirds that are believed to rely on scarce and unpredictable resources and have developed specific foraging strategies to exploit these resources. Frigatebirds are tropical seabirds that rely on subsurface predators such as tuna or cetaceans to feed. We studied the foraging strategy at sea of great frigatebirds breeding on Europa Island in the Mozambique Channel using satellite transmitters and altimeters. When foraging, birds moved at slow speeds (average $16.4 \mathrm{~km} \mathrm{~h}^{-1}$ ) and stayed at an average altitude of $180 \mathrm{~m}$, continuously climbing and descending. During climbs, they reached high altitudes (maximum $2867 \mathrm{~m}$ ) and during descent rarely came close to the surface to feed. Birds came to the surface on average 6.2 times $\mathrm{d}^{-1}$. Feeding opportunities occurred only during the day, peaking early in the morning and late in the afternoon. Frigatebirds foraged over extensive distances, up to $612 \mathrm{~km}$ from the island, usually during the incubation or post-breeding periods, concentrating their effort in the western oceanic waters of the channel where overall productivity, although low, was still higher than in the eastern part of the channel. The higher productivity in the western waters is due to the presence of a persistent field of mesoscale anticyclonic gyres. Birds tended to avoid the centre of cold eddies and remained at the edge of eddies. When brooding chicks, birds foraged closer to the island, at an average distance of $94 \mathrm{~km}$, mainly in the northwest of the island, in the vicinity of shallow waters of the Bassas da India Bank. During both long and short trips, birds did not return to the same area. Diet was composed essentially of flying-fish and Ommastrephid squids. The results of the study indicate that the strategy of frigatebirds is based on wide ranging foraging directed toward scarce prey patches that are encountered irregularly, and are not predictable in exact location at a coarse scale. At a mesoscale level, birds appear to favour large areas with slightly enhanced productivity such as a zone of strong eddies. Since they feed in close association with subsurface predators, mainly tuna in our area, it can be predicted that large predators such as seabirds or tuna are spread over extensive areas and have an unpredictable localisation at a coarse scale, but have some specific preferences on a regional scale.
\end{abstract}

KEY WORDS: Europa Island · Satellite transmitters $\cdot$ Altimeters $\cdot$ Flying-fish $\cdot$ Ommastrephid squids $\cdot$ Tunas Resale or republication not permitted without written consent of the publisher

\section{INTRODUCTION}

Tropical oceanic waters are among the least productive of marine habitats, and the low phytoplankton production affects total biomass at higher trophic levels.
As a consequence, it is generally assumed that in oceanic tropical 'blue waters' resources for marine top predators like tuna or seabirds are low in abundance and have an unpredictable and patchy distribution (Ashmole 1971, Ainley \& Boekelheide 1983, Bertrand 
et al. 2002). These features likely account for the evolution of proficient locomotion in these predators which allows them to travel over vast oceanic areas, searching for patchy resources. For example, tuna are highly migratory, powerful swimmers that range over entire tropical basin waters and have numerous physiological adaptations that facilitate this strategy (Block \& Stevens 2001). Similarly, tropical seabirds are more proficient flyers than temperate or polar species (Ballance \& Pitman 1999). Hypotheses about the patchiness and unpredictability of tropical marine resources have rarely been tested (Haney 1987, Ribic \& Ainley 1997), mainly because of the difficulty of studying marine organisms in the open ocean, yet they are of particular importance, not only for fisheries management strategies, but also in order to gain a better understanding of the functioning of tropical marine ecosystems.

Seabirds feed at a range of trophic levels on planktonic and nektonic prey and are unique among marine animals in that, although they are wholly dependent upon the ocean to feed, they live at or above the surface. They can be easily studied because of this and especially because they breed on land, where they can be handled easily. Thus, they provide unique vectors to test hypotheses about the structure and heterogeneity of the open ocean that otherwise would be impossible to test (Ballance et al. 1997) and are therefore particularly instructive as biological indicators of ecosystem state (Furness \& Greenwood 1993). The foraging ecology of tropical seabirds has been studied at various places of the world during oceanic cruises (e. g. Bailey 1968, Pocklington 1979, Ballance et al. 1997, Spear et al. 2001). Surprisingly, whereas there is abundant literature on the foraging ecology of seabirds in polar and temperate areas based on newly developed telemetry systems, no such research on the individual foraging strategies of tropical seabirds has been carried out aside from a few preliminary studies (Ballance 1995, Weimerskirch et al. 2003). One characteristic of the foraging strategy of tropical seabirds is to feed primarily in multi-species flocks in association with subsurface predators, especially tuna but also other large fishes or dolphins (Au \& Pitman 1986), that bring prey close to the surface in the open ocean (Ballance \& Pitman 1999) and in coastal environments (Jaquemet et al. 2004). Thus, the study of the foraging behaviour of tropical seabirds allows us to test hypotheses not only about the distribution and foraging ecology of seabirds, but also on the distribution of large predatory fishes like tuna.

The constraints imposed by the low productivity of tropical oceanic environments suggest that tropical seabirds may adopt appropriate foraging strategies, together with energy efficient flight (Ainley \& Boekel- heide 1983, Flint \& Nagy 1984), and that low productivity might also select for specific life history traits such as low fecundity but high adult survival (Weimerskirch 2001). Frigatebirds are probably extreme examples of this evolution. They are strictly tropical, large, long-lived, pelagic seabirds with extremely efficient flight, in part because they use thermals to soar before gliding over long distances. They spend their foraging time at high altitudes to locate patches of prey, and only come close to the surface to feed (Weimerskirch et al. 2003). Like many tropical seabirds they rely to a large extent on association with subsurface predators, even more than other seabirds because they are unable to dive or rest on the water surface, and are thus specialised in snatching prey just at, or above, the sea surface (Ashmole 1971) and possibly scavenging on injured or disoriented prey of marine predator schools. Although they are well known for their habit of kleptoparasitising other seabirds, this technique represents only a minor proportion of their food source (Vickery \& Brooke 1994, Le Corre \& Jouventin 1997a).

The purpose of this work is to provide the first comprehensive study on the foraging strategies of a tropical seabird and to test some hypotheses about the effects of low predictability and patchiness of marine resources on a top predator. Specifically, we document the foraging ecology of great frigatebirds (Fregata minor) and test 2 predictions: (1) If the location of prey is patchy and unpredictable, a marine predator at the individual level will not move directionally toward a specific area and will not return consistently to the same foraging sector from one trip to the next, as do many seabirds in temperate or polar areas. (2) At the population level, birds will disperse over large areas to forage rather than clustering in specific sectors where food is concentrated by predictable oceanographic factors.

\section{MATERIALS AND METHODS}

The study was carried out on Europa Island $\left(22.3^{\circ} \mathrm{S}\right.$, $40.3^{\circ} \mathrm{E}$ ), in the Mozambique Channel (Fig. 1) between 18 August and 30 September 2003. At this time, all stages of breeding can be observed in great frigatebirds, from egg-laying to rearing of large chicks. The population of great frigatebirds on Europa is in the region of 700 to 1100 pairs, with the large colony made up of several subcolonies (numbering 2-3 to 30-50 nests) located in the central part of the island in a dry forest of Euphorbia stenoclada (Le Corre \& Jouventin 1997b). The study colonies were monitored daily in the afternoon from under forest cover at distances of 30 to $50 \mathrm{~m}$ taking into account the presence of adults on the nest. The location of each subcolony was determined with a GPS (Global Positioning System), and each nest within a subcolony 


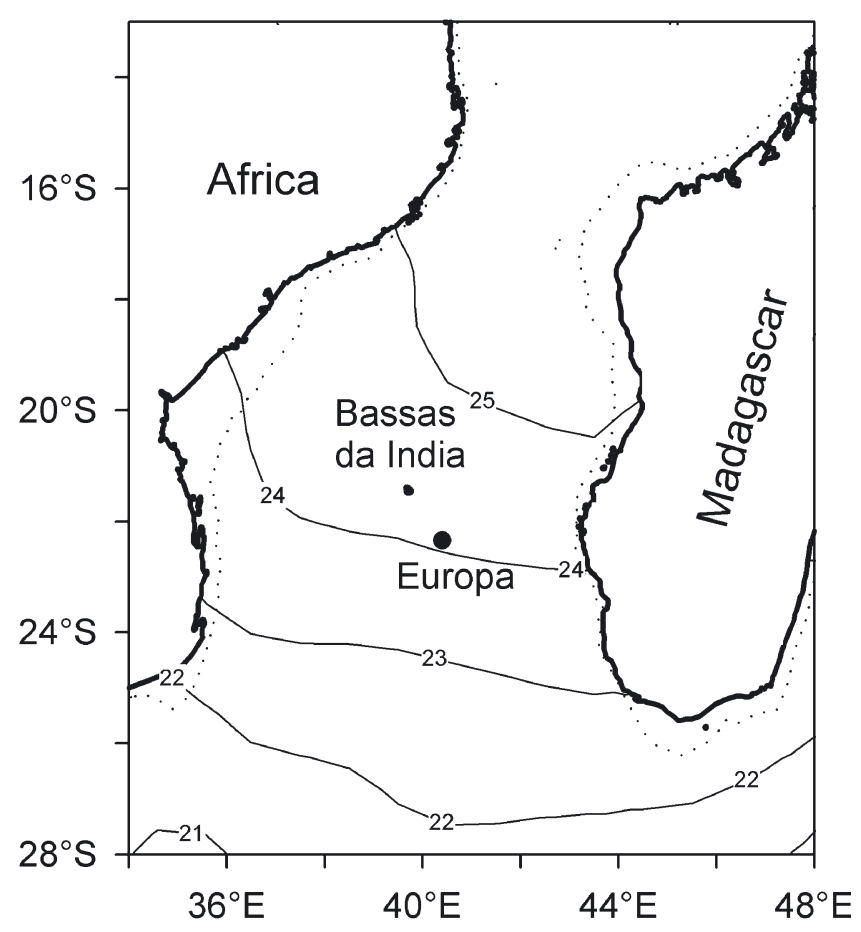

Fig. 1. The Mozambique Channel showing the $-200 \mathrm{~m}$ depth contour (dotted line) separating neritic shelf areas from oceanic waters, and the sea-surface temperature isotherms $\left({ }^{\circ} \mathrm{C}\right)$ in September 2003

was plotted. Males and females were distinguished using plumage characteristics; males have completely black plumage and a black bill, while females have dark plumage with a white belly, bluish beak and pink eye ring. To avoid desertion or pirating of nest material by non-breeders, since frigatebird colonies are very sensitive to disturbance, birds were handled only at night: they were captured after being blinded with a powerful spotlight. We only captured birds that were incubating or brooding. Birds were rapidly captured by hand, fitted with either transmitters or altimeters, before being returned to their nests. Birds always subsequently resumed their breeding duties. Neither the bird handling technique employed, or the attachment of equipment resulted in nest desertion by targeted birds. However breeding success in frigatebirds is naturally low (Diamond 1975, H. Weimerskirch pers. obs.), so rate of nest desertion is high. Five birds that we handled stopped breeding between 5 and $25 \mathrm{~d}$ after being handled, because either they or their partners deserted. This allowed us to study successive foraging trips of breeding birds followed by trips made by the same bird as a failed breeder, i.e. no longer constrained by breeding activites.

The stomach contents of 34 birds were obtained by collecting the spontaneous regurgitation of 14 adult birds captured at night, 8 roosting immatures and 12 chicks after they had been fed by an adult. Food items were identified using keys by Smith \& Heemstra (1986) for fish, Clarke (1986) and Nesis (1987) for squids and our own reference collections.

To study the movements of frigatebirds, we fitted 9 birds (2 males and 7 females) with PTT 100 satellite transmitters (Microwave telemetry) weighing $18 \mathrm{~g}$ ( 2 transmitters) and $30 \mathrm{~g} \mathrm{(7)}$, i.e. 1.2 to $3 \%$ of the mass of adults during 2 to 17 successive foraging trips (50 foraging trips in total). To study vertical movements of birds we used Suunto X6 altimeters (32g) (Suunto Oy) which recorded altitude every min of complete foraging trips. Altimeter data were corrected for shifts in atmospheric pressure using recordings from a fixed altimeter in the colony. This allowed us to measure activity patterns of frigatebirds, and particularly the time spent close to the sea-surface., The transmitters and altimeters were taped on the back or tail feathers of targeted birds using Tesa ${ }^{\circledR}$ tape.

Foraging trips were separated into 'long trips' which included all those flown during the incubation period and the trips longer than $72 \mathrm{~h}$ made by post-breeders. Short trips included all those performed by birds brooding chicks and the trips shorter than $72 \mathrm{~h}$ made by post-breeders (see Fig. 2). Post-breeding trips were of similar duration to those carried out before breeding failure, i.e. short trips after brooding, and longer trips after failure during incubation, explaining the bimodal distribution of trips for post-breeders (see Fig. 2). Foraging trips consisted of 2 parts: an outward part which lasted to the point of maximum range from the colony and a return part back to the colony. Because individuals were tracked for several successive trips, to avoid pseudoreplication problems we analysed data on the trip characteristics using mixed-model ANOVAs. Speed, range or distance covered were the dependant variables, trip segment (return versus outward trip) and time (day versus night) as fixed factors and individual was considered as a random factor.

The locations obtained by the Argos system were filtered following Weimerskirch et al. (1993), allowing for a maximum flight speed of $65 \mathrm{~km} \mathrm{~h}^{-1}$ for frigatebirds (Weimerskirch et al. 2003). Satellite telemetry data provided the location of animals but did not indicate whether birds were moving between colonies and foraging grounds, or foraging. Flight speed can be used as an indicator of foraging activity (Veit 1999, Hyrenbach et al. 2002). We used the same rationale as that used for Procellariiformes (a reduction of flight speed indicates foraging) and modified it for frigatebirds. Frigatebirds continuously climb and descend but tend to remain at high altitude, using their vertical movements to gain altitude by soaring, and then executing long glides to perform horizontal movements (Weimerskirch et al. 2003). To feed they come close to the sea surface. The movement to the 
surface precludes a long glide for commuting, and consequently reduces overall flight speed. We thus used periods with reduced flight speed as an indicator of foraging activity. We define a foraging patch as the area where flight speed between at least 3 successive Argos locations was lower than $10 \mathrm{~km} \mathrm{~h}^{-1}$. Very short time intervals between locations can produce erroneous estimates of speed because of the relative inaccuracy of the locations; therefore, we used only pairs of locations at sea separated by more than $30 \mathrm{~min}$.

To quantify foraging areas of frigatebirds we used kernel estimation techniques to delineate foraging ranges and core habitat areas used by frigatebirds fitted with satellite transmitters during the short trips and long trips. We used the fixed kernel method (Worton 1995) and the least square algorithm (Seaman \& Powell 1996). We estimated contour levels including 10 to $90 \%$ of the locations (Wood et al. 2000, Hyrenbach et al. 2002). To characterise the habitat used by frigatebirds, we used bathymetry, sea surface chlorophyll concentration and sea level anomalies. Sea surface chlorophyll concentrations were derived from the SeaWiFS Local Area Coverage (LAC) ocean color data, acquired and processed at the IRD-SEAS tracking station in La Réunion (under agreement with NASA). Individual swaths of satellite passes were assembled to cover the whole Mozambique Channel and transit averages were performed on a $7 \mathrm{~d}$ period to reduce the proportion of cloudy pixels. The original spatial resolution $(1 \mathrm{~km})$ was enlarged to $2 \mathrm{~km}$. Concentrations were log-transformed because of the nonnormal distribution of the values. Sea surface height (SSH) anomalies and geostrophic current strength were obtained from the AVISO database of the CLS Physical Oceanography Division (www.aviso.oceanobs. $\mathrm{com} /$ ). To examine whether birds selected some areas with enhanced productivity or specific SSH, we estimated (by satellite telemetry, see Results) the distribution of chlorophyll concentration (for every $2 \mathrm{~km}^{2}$ of the maximum foraging range of the Europa birds) and of $\mathrm{SSH}$ (for every $10 \mathrm{~km}^{2}$ of the maximum foraging range of the Europa birds) available to birds from Europa. We compared this distribution of available productivities and $\mathrm{SSH}$ to that of waters over which birds travelled (crossed) and foraged.

For each foraging trip we estimated a destination bearing as the bearing between the colony and the first foraging patch (or the most distant point of a trip when no foraging patch was detected). To measure how consistent birds were in returning to their previous destination we measured the difference in bearing between trips.

Statistical analyses were performed with STATISTICA 6.0. Averages values are given $\pm 1 \mathrm{SD}$.

\section{RESULTS}

Great frigatebirds foraged at sea for trips lasting between 3 and $12 \mathrm{~d}$ (average $5.8 \pm 1.8, \mathrm{n}=52$ ) when incubating, and 1 to $3 \mathrm{~d}$ (average $1.1 \pm 0.7, \mathrm{n}=21$ ) when brooding chicks. Post-breeding birds spent a more variable time at sea (average $3.1 \pm 2.8$, range 0.5 to $9, \mathrm{n}=$ 27) (Fig. 2). The duration of foraging trips of incubating birds fitted with PTTs and altimeters was not significantly different from that of non-equipped birds $(6.5 \pm$ $2.6 \mathrm{~d}$ and $5.7 \pm 1.6 \mathrm{~d}$ respectively, mixed-model ANOVA $F_{1,23}=1.66, \mathrm{p}=0.216$ ). The comparison for brooding birds cannot be made because the duration of trips of non-equipped birds was not known, due to the shortness of the trips and daily monitoring of nests.

\section{Activity pattern}

When foraging, great frigatebirds stayed at an average altitude of 180 meters, continuously climbing and descending (Fig. 3). During climbs they reached high altitudes (average maximum altitude $1764 \pm 620 \mathrm{~m}$, range 864 to $2867 \mathrm{~m}$ ). They came close to the surface $(0<$ altitude $<10 \mathrm{~m})$ on average $6.2 \pm 2.9$ times $\mathrm{d}^{-1}$ (range 0.5 to 8.5 times $\mathrm{d}^{-1}$ ) and spent on average 4.9 min close to the surface before returning to higher

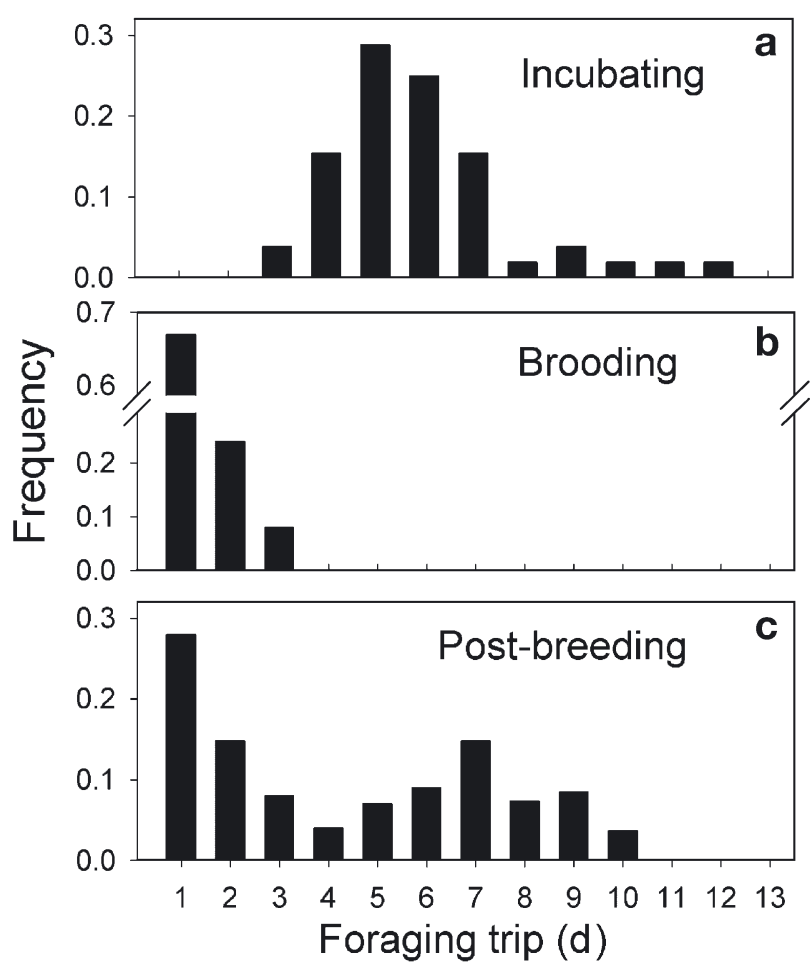

Fig. 2. Fregata minor. Duration frequency of foraging trips during (a) incubation ( $\mathrm{n}=52$ trips), (b) brooding ( $\mathrm{n}=21$ ) and (c) post-breeding $(\mathrm{n}=27)$ 

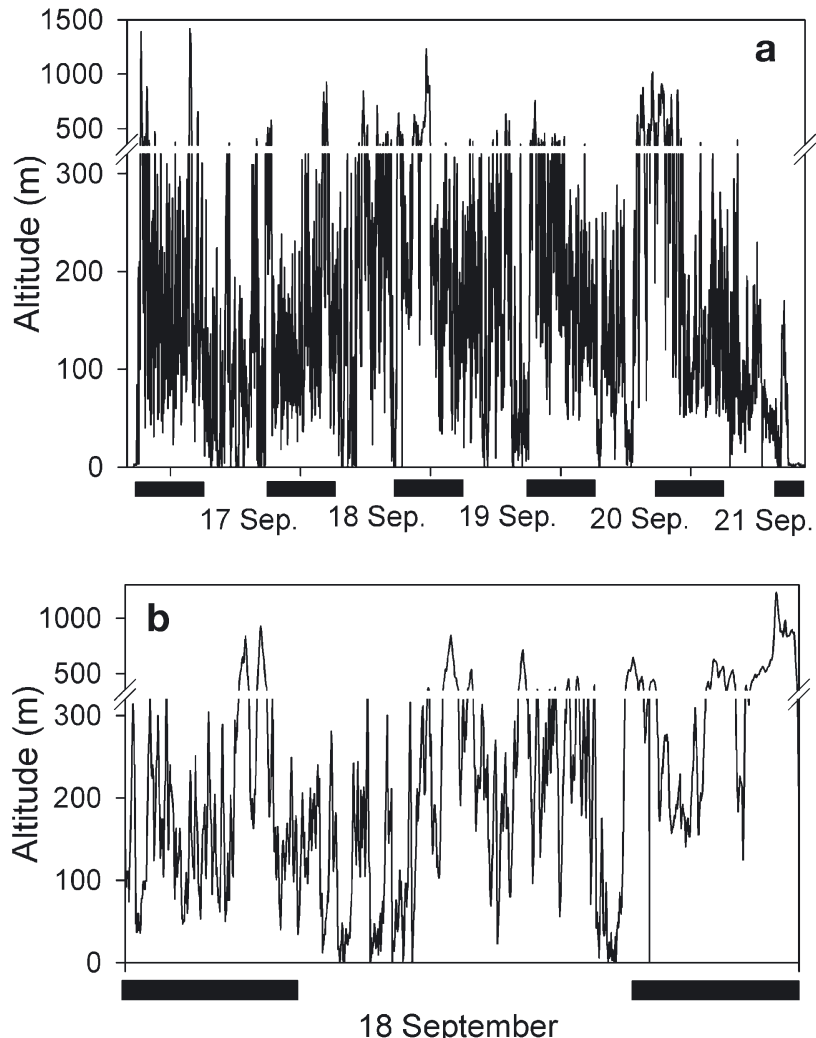

Fig. 3. Fregata minor. Changes in altitude of a female great frigatebird (a) during a 5 day foraging trip between 16 and 21 September 2003, and (b) on 18 September. Black boxes indicate night-time

altitudes (range 1 to $56 \mathrm{~min}$ ). These feeding opportunities were highly clustered since $44 \%$ of the intervals between 2 successive feeding opportunities were shorter than $1 \mathrm{~h}$, and $78 \%$ shorter than $4 \mathrm{~h}$ and occurred only during the daytime, with peaks early in the morning and late in the afternoon (Fig. 4) indicating that birds feed only during the daytime.

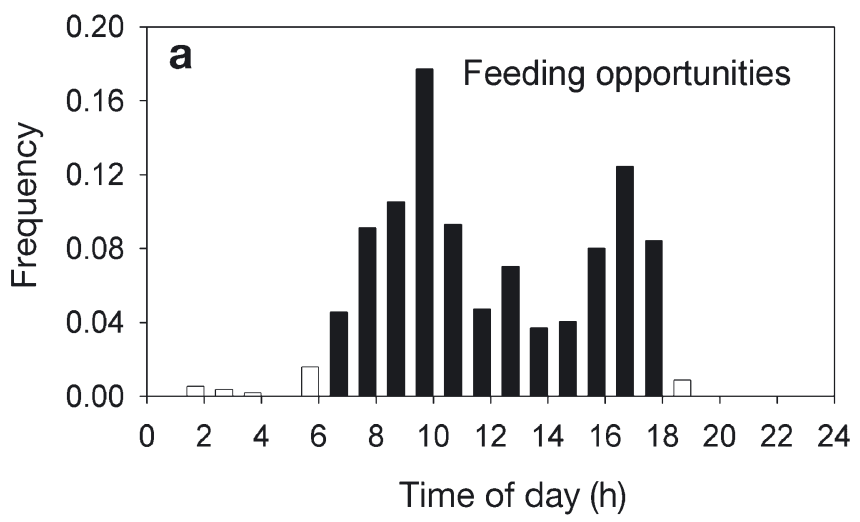

\section{Foraging movements}

Foraging movements of frigatebirds consisted of long looping tracks during long trips, and parallel return trips during short trips (Fig. 5a,b respectively). The average flight speed as determined by satellite telemetry was $16.4 \pm 4 \mathrm{~km} \mathrm{~h}^{-1}$. Flight speeds were higher during the daytime than at night (16.8 versus $14.5 \mathrm{~km} \mathrm{~h}^{-1}$; Wilcoxon test for paired samples, $Z=2.3$, $\mathrm{p}=0.019$ ), but were similar during the outward part of the trip compared to the return part of the trip $(Z=$ $0.16, \mathrm{p}=0.870$ ). Flight speeds were similar during short and long trips (mixed-model ANOVA $F_{1,9}=10.1$, $\mathrm{p}=0.331$ ). During short trips the maximum range was $94 \pm 32 \mathrm{~km}$, and the minimum distance covered $234 \pm$ $74 \mathrm{~km}$, whereas during long trips maximum range and distance covered were $299 \pm 167$ and $1086 \pm 730 \mathrm{~km}$ (maximum 617 and $3701 \mathrm{~km}$ respectively). Putative foraging bouts, i.e. periods when birds reduce flight speeds (see 'Materials and methods'), lasted on average $3.8 \pm 1.5 \mathrm{~h}$, and therefore included several feeding opportunities (as also determined by altimetry that show that feeding opportunities are clustered in time, see above) which tended to be clustered within 1 to $3 \mathrm{~h}$. Similarly, foraging bouts peaked in the morning and in the afternoon (night-time foraging bouts were not considered as foraging bouts since feeding opportunities occur only during the daytime), suggesting that our index of foraging effort through reduced flight speed is a good measure of foraging activity (Fig. 3b). During each trip birds encountered 0 to 16 distinct foraging patches (no clear patch was encountered during half of the short trips) with an average inter-patch distance of $105 \pm 51 \mathrm{~km}(\mathrm{n}=65$, range 4 to $365 \mathrm{~km})$. The distance between the colony and the first patch encountered was strongly related to the maximum range (maximum range $=0.577 \times$ distance to first patch $+36.9, \mathrm{R}^{2}=0.751, \mathrm{p}<0.001$ ) indicating that when

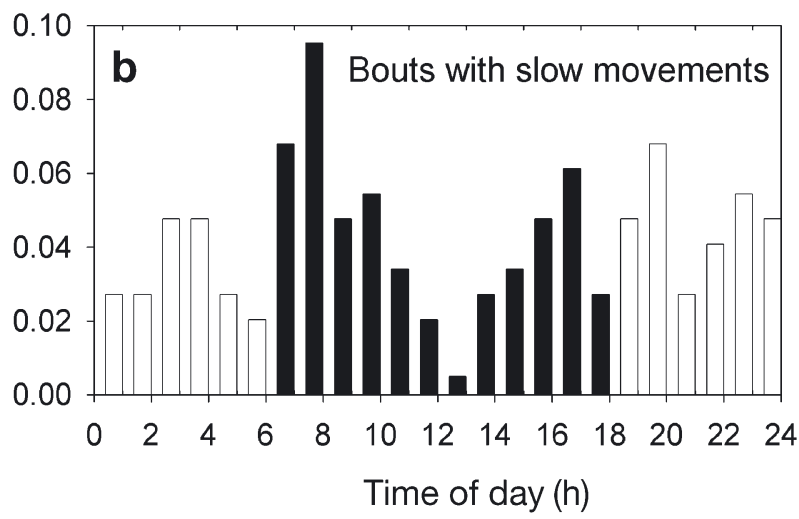

Fig. 4. Fregata minor. Frequency distribution of the timing of (a) feeding opportunities derived from altimetry measurements when birds were close to the surface (below $5 \mathrm{~m}$ ), and (b) foraging bouts derived from satellite telemetry data when birds reduced their flight speed to under $10 \mathrm{~km} \mathrm{~h}^{-1}$ 

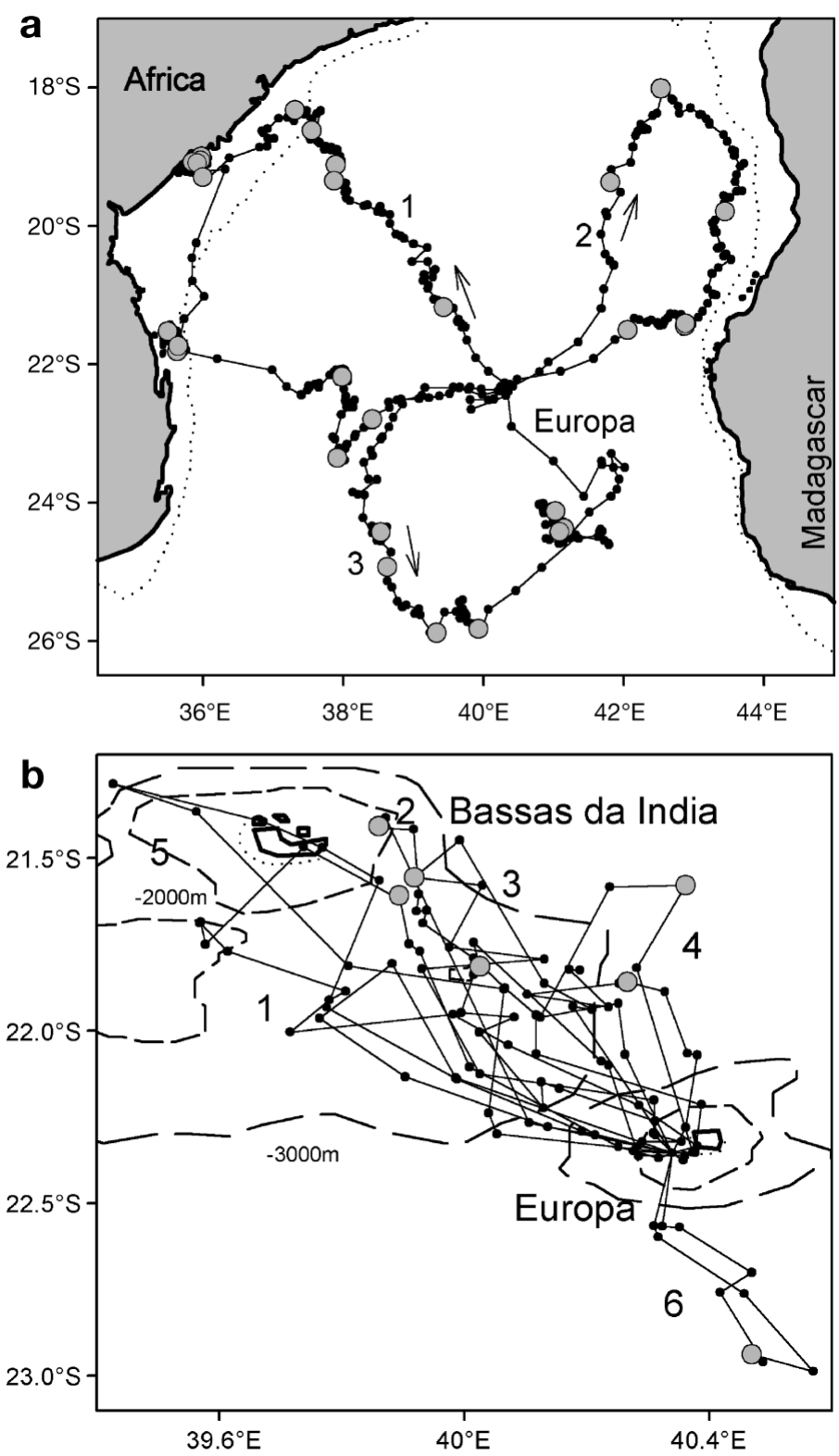

Fig. 5. Fregata minor. (a) Three successive long foraging trips (1 and 2 occurred during incubation and 3 was a post-breeding trip) by the same female (Arrows indicate flight direction) and (b) 6 successive short trips during brooding by another female. •: satellite locations; $\bigcirc$ : putative foraging patches

doing long foraging trips birds do not forage close from the colony on the outward part of the trip but head rapidly to distant waters.

Although they tended to favour some specific areas, such as the shallow waters around Bassas da IndiaJaguar Sea Mount Bank, during successive short trips, as well as during successive long trips, individual birds never returned exactly to the same foraging area from one trip to the next (Fig. 5b). However, the angular deviation of the destination bearing from one trip to the next was much higher for long trips than for short trips $\left(25.5^{\circ}\right.$ versus $88.2^{\circ}$, mixed-model ANOVA $F_{1,7}=2.4, \mathrm{p}=0.012$ ), indicating that during successive short trips birds tended to fly in the same direction (average bearing 310, north-north east) whereas the flight bearing changed from one long trip to the next.

\section{Foraging habitat}

The foraging zone of Europa birds ranged over the southern part of the Mozambique Channel, up to the coasts of Africa and Madagascar (Fig. 6a). During the brooding period and post-breeding short trips, the

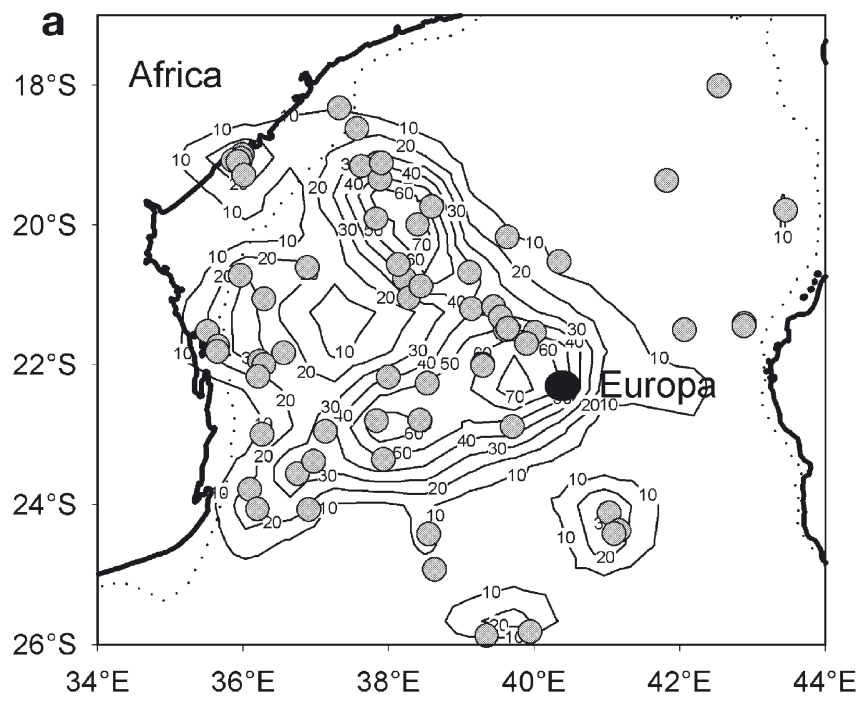

b

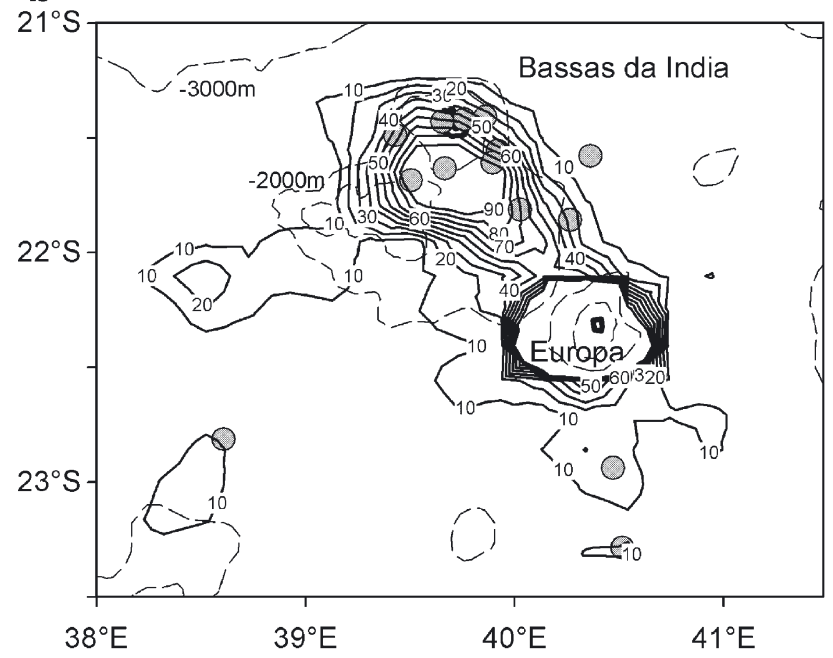

Fig. 6. Density contour plots from kernel estimates of the number of locations during (a) all long foraging trips in the Mozambique Channel and (b) short foraging trips in the vicinity of Europa. $O$ : location of putative foraging patches 
Fig. 7. (a) Composite image of the Mozambique Channel showing maximum chlorophyll (chl) concentrations (ln chl $\left.\left[\mathrm{mg} \mathrm{m}^{-3}\right]+0.001\right)$ derived from Sea WiFS between 5 and 28 September 2003. Large green dot is Europa Island. Grey dots represent bird locations during the study period. (b) Frequency distributions of ln chl concentration present (upper panel) in the Mozambique Channel (same area as depicted in [a]), present in areas over which birds flew (middle panel) and present in areas where birds foraged (lower panel)

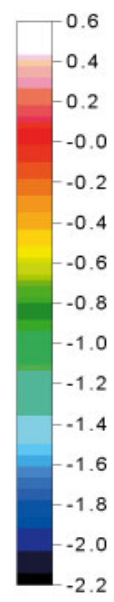

Ln Chlor $\left(\mathrm{mg} / \mathrm{m}^{3}\right)$ $+0.001$
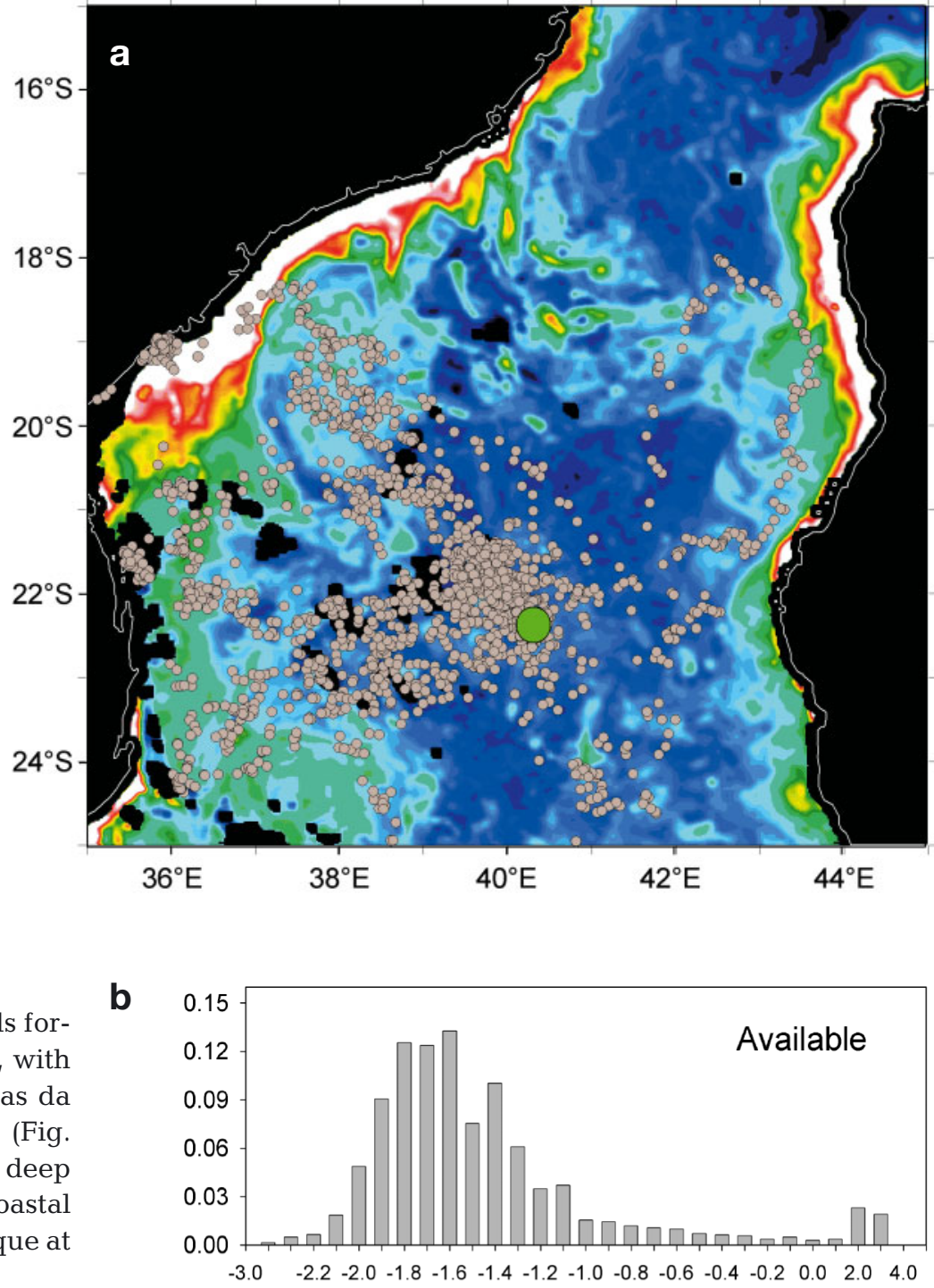

a maximum distance of $617 \mathrm{~km}$ (Fig. 6a).

Frigatebirds foraged mainly over oceanic waters of the Mozambique Channel (92\% of the locations). The remaining locations were over neritic waters (depth $<200 \mathrm{~m}$ ) along east Africa. Apart from the coastal waters off Africa, the productivity in the Mozambique Channel is low ( 0.1 to $0.6 \mathrm{mg} \mathrm{m}^{-3}$ ) but the western oceanic part where frigatebirds spent most of their time has a higher overall production than the eastern part (Fig. 7a). Considering the meridian $39^{\circ} \mathrm{E}$ as a separation between western and eastern parts, the median values of the chlorophyll concentration displayed in the composite image were $0.236 \mathrm{mg} \mathrm{m}^{-3}$ in the west and $0.177 \mathrm{mg} \mathrm{m}^{-3}$ in the east. However, in this area the productivity in the foraging patches was not different from that in the areas which birds only crossed (mixedmodel ANOVA, $F_{1,8}=0.25, \mathrm{p}=0.627$, see also Fig. 7b). b

\section{-}

maximum foraging range was $151 \mathrm{~km}$. Birds for-
aged mainly to the northwest of the island, with the core area being centred over the Bassas da India Bank and its southern surroundings (Fig. 6b). During long trips birds dispersed over deep waters located at the west of Europa, and coastal
waters along the African coast of Mozambique at $36 \mathrm{E}$ $38^{\circ} \mathrm{E}$ $42 \mathrm{E}$
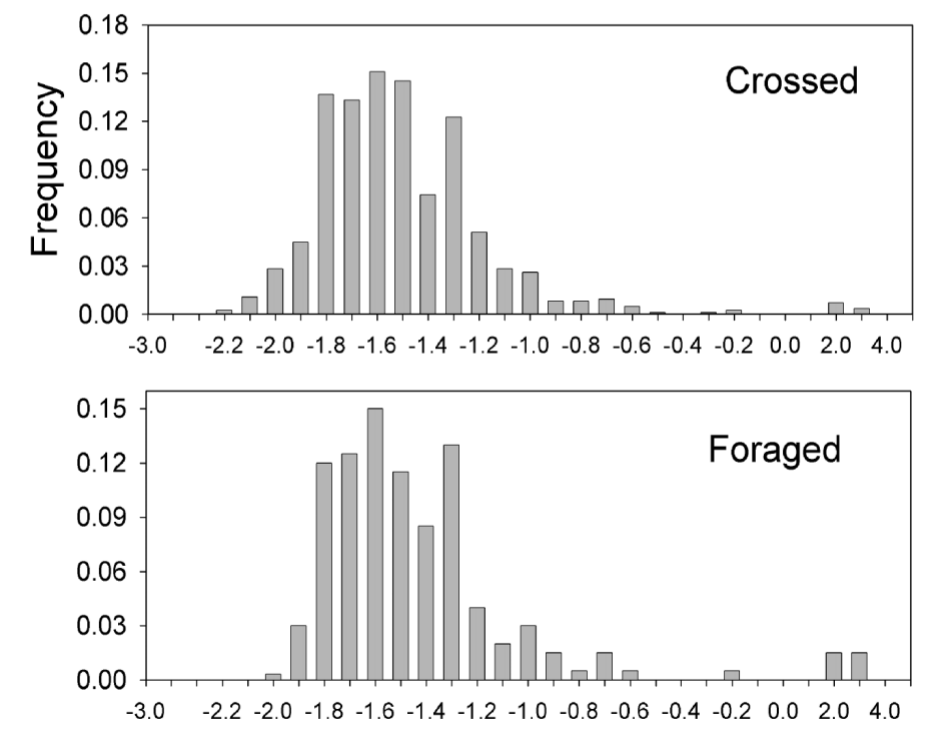

Ln Chl concentration $\left(\mathrm{mg} \mathrm{m}^{-3}\right)+0.001$ 
Fig. 8. (a) Sea surface height anamolies (SSHa) in the Mozambique Channel between 13 and 18 September 2003. Large green dot is Europa Island. Black dots represent locations of frigatebirds during this time. Positive SSHa associated with warm anticyclonic eddies are in red and negative SSHa associated with cold cyclonic eddies are in blue. (b) Frequency distributions of SSHa present (upper panel) in the Mozambique Channel (same area as in [a]), present in areas over which frigatebirds crossed (middle panel) and present in areas where they foraged (lower panel)

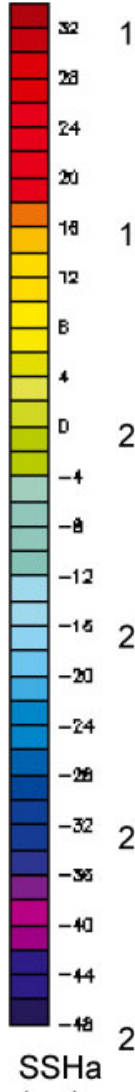

(cm)

The western part of the Channel is a zone of strong eddies (Fig. 8a) that slowly move south. Birds tended to avoid the zones of strongest sea-level anomalies, especially negative anomalies (Fig. 8a,b) and remain at the edge of the warm and cold eddies, in the zone of probable higher geostrophic current strength. However, the geostrophic currents were not stronger in the foraging patches than those currents in the zones crossed by the birds (mixed-model ANOVA, $F_{1,8}=0.01$, $\mathrm{p}=0.985)$.

\section{Diet}

The diet of great frigatebirds was composed mainly of fish $(77 \%$ of the prey: $45 \%$ Exocoetidae, $6 \%$ Hemirhamphidae, $2 \%$ Coryphaenidae, $1 \%$ Scombridae, $1 \%$ Antennariidae, $1 \%$ Sternoptychidae and $21 \%$ unidentified), 19\% squid (almost exclusively Ommastrephidae: Sthenoteuthis oualaniensis) and $4 \%$ crustacean, probably ectoparasites of fish (diet by number, $\mathrm{n}=172$ prey items). b
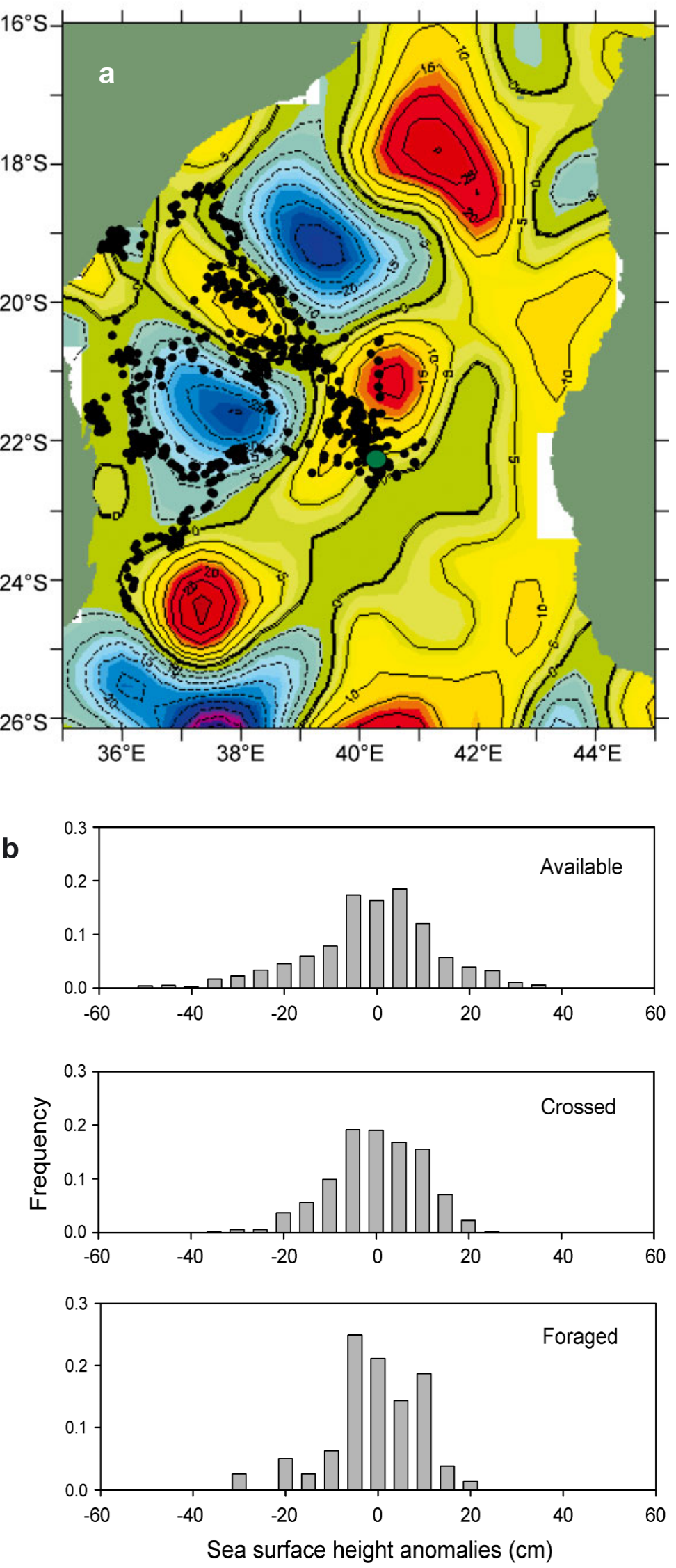


\section{DISCUSSION}

\section{Foraging strategy of frigatebirds}

Frigatebirds are well known for their pirating behaviour but it is generally recognized that this behaviour represents a minor source of energy for them (Vickery \& Brooke 1994, Le Corre \& Jouventin 1997a). Great frigatebirds are frequently observed foraging at the coast or inland at most places where they breed, including Europa Island, preying upon hatchling green turtles (Lagarde et al. 2001), or chicks of sooty terns $(\mathrm{H}$. Weimerskirch pers. obs.), or pirating other seabirds (Le Corre et al. 1997b), but the importance of these feeding strategies in the total energy requirements of breeding birds has never been investigated. Our results on individual tracks of incubating and brooding birds show that these strategies are likely to be unimportant for breeding birds when compared with offshore foraging. All birds tracked headed straight to offshore habitats to forage and did not remain on the island or in its immediate vicinity. This suggests that coastal or inland foraging is less productive than offshore foraging and may only be performed by non-breeding birds with lesser energy requirements than breeding individuals.

Compared with any other seabird, frigatebirds have a very specific flight pattern based primarily on energy saving: they use thermals to gain altitude by soaring, and then glide to move horizontally (Weimerskirch et al. 2003, this study). The particular flying style of frigatebirds is made possible by particular morphological adaptations (lowest wing loading of all birds) which results in low horizontal speed, the lowest for any flying seabird species (Spear \& Ainley 1997). Yet our study showed that, in contrast to magnificent frigatebirds (Fregata magnificens) that remain close to the breeding grounds (Weimerskirch et al. 2003), great frigatebirds are able to forage at great distances from their breeding grounds, similar to that of large seabirds like albatrosses which are able to move at much greater speeds (e.g. Weimerskirch 1998). This is made possible by the propensity of frigatebirds to move continuously during day and night, and to never completely stop moving either to forage, to rest or sleep on the water. Indeed, frigatebirds cannot land on the sea surface because of their permeableplumage, and thus have to fly continuously.

Frigatebirds appear to encounter feeding opportunities infrequently (on average every $105 \mathrm{~km}$ ), suggesting that resources are scarcely distributed. When at a food patch, they come close to the surface several times, and feeding bouts last on average $3.8 \mathrm{~h}$. The foraging strategy of frigatebirds is thus to cover large distances in search of food patches. To locate these feed- ing opportunities, great frigatebirds fly at high altitudes. Several authors have pointed out the possible relationship between the low productivity of tropical waters and the flight proficiency of tropical seabirds (Ainley \& Boekelheide 1983, Ballance et al. 1997). With decreasing prey availability or patchiness, selection should favour species with efficient searching techniques and/or low flight costs. Frigatebirds are probably extreme in this respect with their extremely low costs of foraging due to their specific flight patterns. Frigatebirds breeding in the Mozambique Channel are surrounded by oceanic waters relatively poor in resources, but their flight patterns allow them to cover extensive distances searching for ephemeral and dispersed prey patches probably made available by subsurface predators.

\section{Association with subsurface predators}

During the study period, Great frigatebirds fed on epipelagic prey, mainly flying-fish and to a lesser extent flying-squids (Ommastrephidae). Because frigatebirds can only take prey while in flight at the surface or above the surface, and are unable to sit on the water, or dive, these prey must be available at the sea surface. In the Pacific Ocean (Ashmole \& Ashmole 1967, Harrison et al. 1983, Au \& Pitman 1986), and also in the Mozambique Channel (unpubl data), feeding frigatebirds are generally observed in multispecific flocks (with terns and boobies), associated with subsurface predators that drive their prey to the surface, such as surface feeding tuna and dolphins. Ommastrephid squids and flying-fish are often preyed upon by skipjack or yellowfin tuna (Thomas \& Kumaran 1962, Kornilova 1980, Roger 1994, Potier et al. 2002). Feeding opportunities occur mainly during the daytime as indicated by the lack of surface flying by frigatebirds at night, with feeding peaks in the morning, and in the evening. Similarly, the feeding activity of skipjack tuna, the major tuna species with which seabirds associate and one of only 2 species of tuna (the other species is the yellowfin tuna) which exhibits a strong tendency to school in surface waters, takes place in the early morning and late afternoon (Froese \& Pauly 2003). Although data on tuna foraging behaviour are few, these results reinforce the probability of a close association between frigatebirds and tunas and suggest that the location of foraging bouts of frigatebirds could therefore be a good indicator of the presence of subsurface predators, especially tuna species feeding close to the surface. Similarly, in the eastern tropical Pacific, tuna fishers call frigatebirds tuna birds because of their close association (L. Ballance pers. comm.). 


\section{Predictability of feeding opportunities}

To examine whether the location of subsurface predators is predictable and related to specific oceanographic features, it is necessary to separate long foraging trips from short trips. During the long foraging trips birds are not time constrained and are able to disperse extensively away from the central breeding place. Thus they should potentially be able to select specific oceanographic features where prey are abundant and their location predictable. Our results show that during long trips frigatebirds do not return to the same oceanographic sector from one trip to the next as many temperate and polar predators do. Foraging patches are scattered over the entire western Mozambique Channel (Fig. 6a). These results suggest that the location of foraging patches is probably not predictable, at least at a coarse scale. At a larger mesoscale, some patterns emerge. Birds do not forage equally in all directions from Europa but rather most foraging takes place in the western part of the Mozambique Channel where overall chlorophyll concentrations, although low (on average $0.24 \mathrm{mg} \mathrm{m}^{-3}$ ) are still higher than in the eastern part of the Channel. This east-west delineation may be due to a persistent field of mesoscale anticyclonic gyres, composed of 3 major eddies located from $16^{\circ} \mathrm{S}$ to $25^{\circ} \mathrm{S}$ moving very slowly southward (Schouten et al. 2003). Associated with these eddies are cyclonic vortices in the westernmost part of the Channel, that can enhance productivity (Zubkov \& Quartly 2003). In addition to this eddy system, the coastal waters off Africa, especially the Sofala Bank, have very high productivity through the year due to the extent of the continental shelf and enrichment by large incoming rivers. Some individual frigatebirds visited this area from Europa, but most of the birds remained in unproductive oceanic waters and did not actively forage in waters more productive than those encountered while commuting. In these oceanic waters, the dynamics of the eddies system probably makes the precise location of zones of enhanced productivity and especially of feeding subsurface predators more unpredictable. However birds tended to avoid the centres of the cyclonic eddies (negative anomalies) where production is likely to be lower than at the edge or centre of anti-cyclonic warm mesoscale eddies (McGillicuddy et al. 1998, Lima et al. 2002). This preference for the edge of mesoscale eddies was also found in another seabird, the grey-headed albatrosses (Nel et al. 2001). Thus, during long foraging trips frigatebirds select large areas where overall productivity may be enhanced, but probably search more randomly at a coarse scale for dispersed prey patches whose precise location is not predictable.
During short trips when brooding, birds are time and energy constrained: they have to bring food frequently to their chick and thus have a restricted range of $150 \mathrm{~km}$ around the breeding island. During this time the foraging zone and foraging patches are concentrated in a specific sector to the northwest of Europa, corresponding to the Bassas da India-Jaguar Sea Mount where other top predators such as cetaceans, tuna and boobies concentrate (S. Jaquemet unpubl. data), perhaps as a zone of upwelling with increased enrichment. This area may be a zone of increased prey availability. Interestingly, this sector was not foraged by frigatebirds departing for long foraging trips, suggesting that the foraging yield there is lower than that of more distant waters, either as a result of strong interspecific competition close to the island or because this area is overall less productive than more distant waters in the west of the Mozambique Channel.

\section{Conclusions}

The foraging strategy of this tropical species differs markedly from those described in temperate or polar regions. In these colder waters, birds foraging close to the colonies generally tend to concentrate around predictable features, such as those related to bathymetry or tidal forcing, at a small scale, or larger scale features such as fronts (see review in Hunt et al. 1999). Even the most pelagic species such as albatrosses, which share with frigatebirds some remarkable convergences, notably their energy efficient flight and long foraging, appear to concentrate consistently, or at least during some phases of the breeding cycle, on frontal areas or on shelf edges where productivity is enhanced (Weimerskirch 1998, Hyrenbach et al. 2002). Most species tend to return to the same area on succesive trips, displaying a high degree of predictability. The results of this study provide the first information on the way a flying marine top predator forages in tropical waters. The results confirm what has been suspected of many tropical seabirds, i.e. frigatebirds do not cluster at specific oceanographic features. Instead they focus on areas with higher productivity on a regional scale, but the prey patches they feed on are clearly not predictable in space or time. The results also confirm that low cost and long range foragers should be favoured in tropical waters. Because of their close association with other subsurface predators like tuna, long-ranging seabirds like frigatebirds can be used to study the distribution of marine resources in the poorly known tropical oceanic waters. 
Acknowledgements. We thank the Direction Régionale de l'Environnement (DIREN) of Ile de la Réunion for financial support, the Préfet de la Réunion and the Direction of Météo France for authorisation and support to work on Europa, the Forces Armées de la Zone Sud de l'Océan Indien (FAZSOI) for transport to and logistical support on Europa. We thank M. Slepoukha (IRD-US ESPACE) for extracting the Sea WIFS data, L. Ballance and 3 anonymous referees for constructive comments.

\section{LITERATURE CITED}

Ainley DG, Boekelheide RJ (1983) An ecological comparison of oceanic seabird communities of the south Pacific ocean. Stud Avian Biol 8:2-23

Ashmole NP (1971) Seabird ecology and the marine environment. In: Farner DS, King JR (eds) Avian Biology, Vol 1. Academic Press, New York, p 223-286

Ashmole NP, Ashmole MJ (1967) Comparative feeding ecology of seabirds of a tropical oceanic island. Peabody Mus Nat Hist Yale Univ Bull 24

Au DWK, Pitman RL (1986) Seabird interactions with dolphins and tuna in the eastern tropical Pacific. Condor 88: 304-317

Bailey RS (1968) The pelagic distribution of seabirds in the western Indian Ocean. Ibis 110:493-519

Ballance LT (1995) Flight energetics of free-ranging redfooted boobies (Sula sula). Physiol Zool 68:887-914

Ballance LT, Pitman RL (1999) Foraging ecology of tropical seabirds. In: Adams NJ, Slotow RH (eds) Proc 22nd Int Ornithol Congr, Durban, 20-22 Aug, 1998. Birdlife South Africa Johannesburg, p 2057-2071

Ballance LT, Pitman RL, Reilly SB (1997) Seabird community structure along a productivity gradient: importance of competition and energetic constraint. Ecology 78:1502-1518

Bertrand A, Bard FX, Josse E (2002) Tuna food habits related to the micronekton distribution in French Polynesia. Mar Biol 140:1023-1037

Block BA, Stevens ED (2001) Tuna: physiology, ecology and evolution. Academic press, San Diego

Clarke MR (1986) A handbook for the identification of cephalopods beaks. Clarendon Press, Oxford

Diamond AW (1975) Biology and behaviour of frigatebirds Fregata spp. on Aldabra Atoll. Ibis 117:302-323

Flint EN, Nagy KA (1984) Flight energetics of free-living sooty terns. Auk 101:288-294

Froese R, Pauly D (2003) Fishbase. World Wide Web electronic publication, www.fishbase.org

Furness RW, Greenwood JJD (1993) Birds as monitors of environmental change. Chapman \& Hall, London

Haney JC (1987) Ocean internal waves as sources of smallscale patchiness in the seabird distribution on the Blake Plateau. Auk 104:62-70

Harrison CS, Hida TS, Seki MP (1983) Hawaiian seabird feeding ecology. Wildl Monogr 85:1-71

Hyrenbach KD, Fernandez P, Anderson DJ (2002) Oceanographic habitats of two sympatric North Pacific albatrosses during the breeding season. Mar Ecol Prog Ser 233:283-301

Hunt GL, Mehlum F, Russell RW, Irons D, Decker MB, Becker PH (1999) Physical processes, prey abundance, and the foraging ecology of seabirds. In: Adams NJ, Slotow RH (eds) Proc 22 Int Ornithol Congr, Durban, 20-22 Aug, 1998. BirdLife South Africa, Johannesburg, p 2040-2056

Jaquemet S, Le Corre M, Weimerskirch H (2004) Seabird community structure in a coastal tropical environment: importance of natural factors and of Fish Aggregating Devices (FADs). Mar Ecol Prog Ser 268:281-292

Kornilova GN (1980) Feeding of yellowfin tuna, Thunnus albacares, and bigeye tuna, Thunnus obesus, in the equatorial zone of the Indian ocean. J Ichthyol 20:111-119

Lagarde F, Le Corre M, Lormée H (2001) Species and sexbiased predation on hatchling green turtles by frigatebirds on Europa Island, western Indian Ocean. Condor 103:405-408

LeCorre M, Jouventin P (1997a) Kleptoparasitism in tropical seabirds: vulnerability and avoidance responses of a host species, the red-footed booby. Condor 99:162-168

LeCorre M, Jouventin P (1997b) Ecological significance and conservation priorities of Europa Island (Western Indian ocean), with special reference to seabirds. Rev Ecol Terre Vie 52:205-220

Lima ID, Olson DB, Doney SC (2002) Biological response of frontal dynamics and mesoscale variability in oligotrophic environments: biological production and community structure. J Geophys Res 107 (C8):10.1029/2000JC000393

McGillicuddy DJ, Robinson AR, Siegel DA, Jannasch HW and 5 others (1998) Influence of mesoscale eddies on new production in the Sargasso Sea. Nature 394:263-266

Nel DC, Lutjeharms JRE, Pakhomov EA, Ansorge IJ, Ryan PG, Klages NTW (2001) Exploitation of mesoscale oceanographic features by grey-headed albatross Thalassarche chrysostoma in the southern Indian Ocean. Mar Ecol Prog Ser 217:15-26

Nesis KN (1987) Cephalopods of the world. Squids, cuttlefishes, octopuses and allies. T. F. H. Publications, New Jersey

Pocklington R (1979) An oceanographic interpretation of seabirds distributions in the Indian Ocean. Mar Biol 51: 9-21

Potier M, Lucas V, Marsac F, Sabatié R, Ménard F (2002) Ongoing research activities on trophic ecology of tuna in equatorial ecosystems of the Indian Ocean. In: Ardill $\mathrm{D}_{\text {, }}$ Anganuzi AA (eds) Indian Ocean Tuna Commission Proceedings. Commission (TOTC), Victoria 5:309-315

Ribic CA, Ainley DG (1997) The relationships of seabirds assemblages to physical habitat features in Pacific equatorial waters during spring 1984-1991. ICES J Mar Sci 54: 593-599

Roger C (1994) Relationships among yellowfin and skipjack tunas, their prey-fish and plankton in the tropical western Indian Ocean. Fish Oceanogr 3:133-141

Saetre R, Da Silva J (1984) The circulation of the Mozambique Channel. Deep-Sea Res II 31:508-585

Seaman DE, Powell RA (1996) An evaluation of the accuracy of kernel density estimators for home range analysis. Ecology 77:2075-2085

Schouten MW, de Ruijter PM, van Leeuwen PJ, Ridderinkhof $\mathrm{H}$ (2003) Eddies and variability in the Mozambique Channel. Deep-Sea Res II 50:1987-2003

Smith MM, Heemstra PC (eds) (1986) Smith's sea fishes. Springer-Verlag, New York

Spear LB, Ainley DG (1997) Flight speed of seabirds in relation to wind speed and direction. Ibis 139:234-251

Spear LB, Balance LT, Ainley DG (2001) Response of seabirds to thermal boundaries in the tropical Pacific: the thermocline versus the Equatorial Front. Mar Ecol Prog Ser 219: 275-289

Thomas PT, Kumaran M (1962) Food of Indian tunas. FAO Fish Rep 6:1559-1667

Veit RR (1999) Behavioral responses by foraging petrels to swarms of krill Euphausia superba. Ardea 87:41-50

Vickery JA, Brooke M de L (1994) The kleptoparasitic inter- 
actions between great frigatebirds and masked boobies on Henderson Island, South Pacific. Condor 96:331-340

Weimerskirch H (1998) Foraging strategies of southern albatrosses and their relationship with fisheries. In: Robertson G, Gales R (eds) Albatross biology and conservation. Surrey Beatty \& Sons, Sydney, p 168-179

Weimerskirch H (2001) The demography of seabirds and its relationship with the marine environment. In: Schreiber EA, Burger J (eds) Biology of marine birds. CRC Press, Boca Raton, FL, p 115-135

Weimerskirch H, Salamolard M, Sarrazin F, Jouventin P (1993) Foraging strategy of wandering albatrosses through the breeding season: a study using satellite telemetry. Auk 110:325-342

Editorial responsibility: Otto Kinne (Editor), Oldendorf/Luhe, Germany
Weimerskirch $\mathrm{H}$, Chastel O, Barbraud C, Tostain O (2003) Frigatebirds ride high on thermals. Nature 421: $333-334$

Wood AG, Naef-Daenzer P, Prince PA, Croxall JP (2000) Quantifying habitat use in satellite tracked pelagic seabirds: application of the kernel estimation to albatross locations. J Avian Biol 31:278-286

Worton BJ (1995) Using Monte Carlo simulation to evaluate kernel-based home range estimators. J Wildl Manag 59: $794-800$

Zubkov M, Quartly GD (2003) Ultraplankton distribution in surface waters of the Mozambique Channel-flow cytometry and satellite imagery. Aquat Microb Ecol 33: 155-161

Submitted: January 20, 2004; Accepted: April 8, 2004

Proofs received from author(s): June 16, 2004 